No menciona tampoco que Molloy haya estudiado el poema «Las calles» de Fervor de Buenos Aires, y divaga sobre el poema sin sacar nada nuevo, siempre con la desventaja de que trabaja no con el texto original de Fervor (utilizado por Molloy), sino con el texto bastante modificado de las Obras completas.

La densidad y sutileza de Borges se le escapan totalmente a la profesora Lagos. En una ocasión recuerda Borges el dictamen de Groussac sobre el Diccionario de la Real Academia Española, «dont chaque édition fait regretter la précédente». Cabe decir lo mismo de cierto sector de la crítica borgeana: dichos críticos se empeñan en volver sobre lo ya hecho, sin tocar, ni por milagro, importantes temas que apenas se han estudiado, como, por ejemplo, el prestar la debida atención a sus lecturas filosóficas y literarias. Si se compara este estudio con otros de amplitud semejante (Tamayo y Ruiz, Irby, Barrenechea, Sturrock), se nota en seguida en el libro de Lagos la falta de una segura dirección y el descubrimiento en profundidad de la materia que va a estudiar, y es evidente que estas imposibilidades no le dejan al crítico otra opción que la de proclamar, con cinismo, "palabras desplazadas y mutiladas, palabras de otros».

\title{
DANiEl BaLderston
}

\section{Tulane University}

Eugene L. Moretta, Gilberto Owen en la poesia mexicana: Dos ensayos. México: Fondo de Cultura Económica, 1985.

En vida, Gilberto Owen fue siempre figura casi marginal a la poesía mexicana, viviendo mucho tiempo lejos de su país, manteniendo contacto sólo con algunos amigos, la mayoría de ellos pertenecientes al grupo de los Contemporáneos. Después de su temprana muerte en 1952, casi olvidado, su obra reunida sólo se publica, muy incompleta, en 1953, y no es sino hasta 1979 cuando sale una edición más completa. Recientemente se ha despertado un renovado interés por su obra, y se ha descubierto que es una de las más complejas y más profundas de los Contemporáneos y de toda la poesía mexicana. Moretta sugiere que la aceptación de la importancia de Owen se fechará en el futuro con la publicación en 1980 - a veintiocho años de la muerte de Owen- de Poesía y alquimia: Los tres mundos de Gilberto Owen, de Jaime García Terrés.

En Gilberto Owen en la poesía mexicana examina Moretta algunos aspectos de esta obra compleja en relación con la de otros escritores. Este estudio de las interrelaciones textuales tiene por propósito: establecer las bases para una mayor comprensión de la obra, no sólo de Owen, sino de todo el grupo de los Contemporáneos; las múltiples interrelaciones entre los diversos subgrupos, y su contexto literario. El primer ensayo se llama «López Velarde y Owen. Examen de una influencia». Propone, sin negar las obvias diferencias, que entre los dos poetas hay nexos tanto de tipo formal como de tipo intelectual, concretamente en la forma de percibir la realidad, para así sugerir una forma de comprender un aspecto de la complicada relación entre el poeta jerezano y los Contemporáneos. A primera vista, sería lícito sospechar que difícilmente pudiéramos encontrar dos poetas menos parecidos entre sí, pero en el fondo existe una importante relación: los dos son poetas de un erotismo torturado por el conflicto con una dimensión espiritual. Moretta ve una profunda semejanza en el sufrimiento y en la máscara 
burlona que emplean los dos para esconder la tristeza y en «la bien evidente y peculiar inquietud a la vez teológica y erótica de ambos autores» (p. 12). Pero la verdadera semejanza se halla en lo que Moretta llama el viaje de la vida, estructura mítica-ritual que desemboca en el regreso desilusionado al hogar. Poemas sintomáticos serían «El retorno maléfico» y «Sindbad el varado». Como aspecto técnico de este «distanciamiento entre el buscador y el objeto de su búsqueda» (p. 15) señala Moretta los desdoblamientos temporales entre presente y pasado.

Otra semejanza importante es la oscilación entre el anhelo de la tradición perdida, inclusive la literaria, y su rechazo por inútil. López Velarde tiende a ver la enajenación presente del individuo, la ruptura de la comunidad armoniosa, contra el fondo de una tradición cultural, y aún más, literaria, a base del regreso del hijo pródigo. A la vez, el poeta presenta esta herencia cultural como responsable, en parte por lo menos, de su enajenación. Hay en él una marcada tendencia a representar los sucesos en términos de un libro, una palabra, lo escrito. En Owen, Sindbad, al haber completado felizmente sus siete aventuras, emprende otra directamente literaria. Más: la paradoja, técnica fundamental de la poesía de López Velarde, se convierte, en Owen, en un discurso de segundo nivel que desmonta el más obvio. La frustración del viaje de Sindbad se contradice por otro discurso interior que enfatiza la fusión de opuestos dentro de un contexto específicamente poético: «el Sindbad de Owen se inventa un reino verbal a resguardo del mundo en donde la literatura no representa más que un peso opresivo» (p. 24). Esta formulación literaria del naufragio parte, como señala Moretta, de una actitud parecida, pero en un punto fundamental muy diferente: para López Velarde, el naufragio es amenaza; para Owen, es un hecho consumado ya, lo cual ayuda a comprender las diferencias de tono entre los dos poetas.

Lejos estamos de agotar este fascinante ensayo; entre otras dimensiones, sugiere una importante relación entre dos poetas y la tradición, más asociada con la prosa, del viaje ritual purificador, empleado de modo fundamental por John Barth, Eliot y tantos más. Vale la pena señalar que tanto en López Velarde como en Owen hay, cuando menos, una sugerencia de que este viaje podría culminar en una experiencia libertadora, y en los dos casos es de tipo erótico. Moretta ve en los famosos versos finales de «Sindbad» la incertidumbre de toda esperanza, pero propone, a la vez, que sugieren la posibilidad de la liberación y el regreso a un estado armonioso. Sería interesante rastrear más esta experiencia en estos dos poetas, para ver hasta dónde se entronca con el desenlace tradicional.

El segundo ensayo del volumen es «Bajo el signo del naufragio. Owen frente a Villaurrutia y Cuesta». Aclara la estrecha amistad literaria entre los tres y el confesado impacto de los dos en la obra de Owen. No se trata, como en el caso de López Velarde, de la influencia de un poeta mayor en otro más joven, sino de tres escritores que durante la misma época iban madurando su obra: «Sindbad el varado», "Canto a un dios mineral» y Nostalgia de la muerte. En las tres obras vuelve la imagen del naufragio y el concepto del poema como recuerdo de un viaje espiritual, un arriesgarse todo y lanzarse rumbo a una identidad nueva. Descubre Moretta la importancia de la tradición del viaje marino en Cuesta y Villaurrutia. Comienza el viaje con lo que llama separación y dirección, y en los tres halla el viaje truncado por el naufragio, seguido de una tercera etapa de quietud, abandono, parálisis. Ya no hay posibilidad del regreso triunfante a la amada regeneradora; en los tres el mundo se presenta caótico, inestable, inconexo.

Este es un libro breve pero importante, cuyo valor no reside exclusivamente 
en los valioses comentarios sobre estos poetas; también presenta todo un programa para futuros estudios. Es hora de gue se lleven a cabo los proyectos señalados, como el examen minucioso de las relaciones entre los diversos grupos dentro del grupo, la influencia de escritores específicos en uno o más miembros, el tema del naufragio y sus relaciones con el sueño, las diversas maneras de comprender y utilizar éste en la poesía, y la estructura del viaje en la poesía de los Contemporáneos y su relación con estructuras parecidas en otros escritores. Sólo así podremos llegar a la meta señalada por Moretta: «una visión de conjunto que nos permitirá reconocerlos como una auténtica generación».

Frank Dauster

\section{Rutgers University}

\section{JuAn José Barrientos, Borges y la imaginación. México: Instituto Nacional de Bellas Artes y Editorial Katún, 1986.}

Borges y la inaginación es una lectura de textos de Borges en la que éstos emergen como reelaboraciones de un número reducido de temas y estructuras narrativas. «Borges sólo cuenta unas cuantas historias.» Esa es la hipótesis que Barrientos se propone verificar mediante la aplicación de conceptos y técnicas de análisis procedentes de Propp, Bremond, Todorov y Genette. Su estudio tiene por objeto la fábula o historia, esto es, la diégesis según Genette. De los otros autores citados ha aprendido a valorar la importancia de la noción de función y las posibilidades de su empleo como eficaz instrumento de análisis textual. Una vez definida su base teórica, y con método claro y lenguaje preciso, Barrientos agrupa los cuentos del escritor argentino alrededor de algunas ideas o temas fundamentales.

En el primer capítulo, titulado «Omnisciencia divina y libre albedrío», estudia los siguientes cuentos: «La muerte y la brújula», «El muerto», "Tema del traidor $\mathrm{y}$ del héroe», "Las ruinas circulares» y «Examen de la obra de Herbert Quain». Barrientos afirma que las historias de dichos cuentos son kaparentemente diferentes, pero en el fondo iguales» (p. 27), e identifica como subtexto de las mismas The Man Who Was Thursday, libro al que caracteriza como uno de los «más borgianos de Chesterton» (p. 26). El problema del libre albedrío y la omnisciencia divina constituyen el trasfondo místico de estos cuentos. Al mismo tiempo, señala nuestro crítico, el modelo del relato policial inglés está presente en ellos, aunque en algunos casos, como en «La muerte y la brújula», Borges rompe con la tradición al hacer que el villano, y no el detective, explique la verdadera historia. Según Barrientos, Bandeira («El muerto»), Nolan («Tema del traidor y del héroe»), Scharlach («La muerte y la brújula») y el ser soñado por un mago ( Las ruinas circulares») son repeticiones, versiones o perversiones del Sunday de Chesterton. Y Otálora, Ryan, Lönnrot y el mago reiteran de algún modo a Syme, el protagonista de la misma novela. Los primeros representarían a Dios, los otros al hombre.

Los cuentos analizados en el segundo capítulo son vinculados por el autor con la idea del Superhombre. A este grupo corresponderían «Deutsches Requiem», «El jardín de senderos que se bifurcan» y "La intrusa». Barrientos señala, en cada caso, la vigencia de la idea de Nietzsche, según el cual el Superhombre «no debía ser sólo despiadado, sino más bien el hombre... que se ha sobrepuesto 